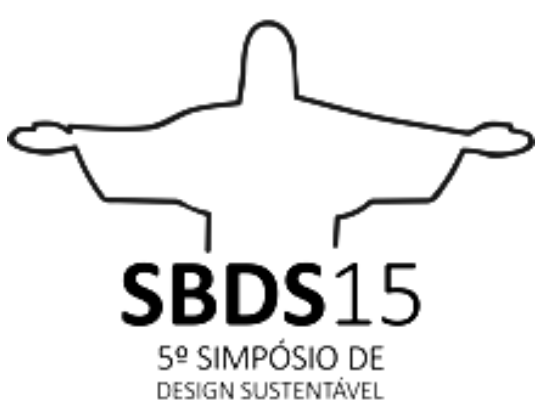

Rio de Janeiro, 11 de novembro a 13 de novembro de 2015

\title{
O DESIGN DE MODA COMO FERRAMENTA NA UTILIZAÇÃO DE PIGMENTOS NATURAIS NA INDÚSTRIA TÊXTIL.
}

\author{
Viana, Teresa Campos, Msc \\ Centro Universitário de Belo Horizonte UNI-BH \\ tecacviana@gmail.com \\ Almeida, Marcelina das Graças de D. Sc \\ Universidade do Estado de Minas Gerais UEMG \\ marcelinaalmeida@yahoo.com.br \\ Ayres, Eliane; D. Sc.; \\ Universidade do Estado de Minas Gerais UEMG \\ eayres.pu@hotmail.com \\ Canaan, Raquel Msc \\ Universidade do Estado de Minas Gerais UEMG \\ raquel.pcanaan@gmail.com
}

\begin{abstract}
Resumo; O presente artigo se propõe a elaborar um levantamento dos benefícios do uso dos corantes naturais e quais as implicações podem trazer ao meio ambiente, assim como uma avaliação das possibilidades de uso mais cuidadoso dos corantes sintéticos. E ao mesmo tempo conhecer os principais movimentos feitos pela sociedade contemporânea na direção para preservação e uso sustentável do meio ambiente. O papel do designer de moda é mostrar a sociedade como se devem utilizar os corantes naturais sem degradar o meio ambiente e mudar os processos de produção da moda para um processo mais sustentável. Este artigo tem a intenção de tratar a importância dos corantes naturais como elemento de diferenciação da moda fazendo um contraponto com a possibilidade de se constituir como um dos meios de usar elementos da natureza sem destruí-la e incentivar a sustentabilidade. As preocupações com o meio ambiente estão na pauta das agendas políticas de todos os países e tem aparecido também como uma importante pauta para a população em geral.
\end{abstract}

Palavras Chave: corantes naturais; indústria têxtil; moda e sustentabilidade. 
Abstract:This article aims to do a survey of the benefits of using natural dyes and what the implications could bring to the environment, as well as an assessment of possibilities for more careful use of chemical dyes. And while knowing the key moves made by contemporary society towards sustainable use and preservation of the environment. The role of fashion designer is to show to the company how to use natural dyes without degrading the environment and change production processes to fashion a more sustainable process. This article intends to address the importance of natural dyes as a differentiation element of fashion making a counterpoint to the possibility of constituting itself as a means of using elements of nature without destroying it and encourage sustainability. Concerns about the environment are on the agenda of the political agendas of all countries and has also appeared as an important agenda for the general population.

Keywords: natural dyes, fabric industry, fashion, sustainability

\section{INTRODUÇÃO}

A utilização dos produtos naturais é uma prática antiga da humanidade. $\mathrm{O}$ uso de ervas e folhas para o alivio de dores, foi provavelmente uma das primeiras formas do homem entrar em contato com a natureza. Na antiguidade, o homem retirava da natureza somente aquilo que ele realmente necessitava para seu conforto e sobrevivência, mas com o aumento da população, o uso dos produtos naturais como era de se esperar aumentou drasticamente, e a natureza passou a sofrer as conseqüências desse uso indiscriminado.

O grande desafio da sociedade contemporânea é utilizar os recursos naturais com equilíbrio e cautela. No mundo atual em que a sustentabilidade ecológica e o cuidado com os resíduos industriais, surgem como conceito, a exigência da sociedade é pela existência de uma indústria menos poluente, que gaste menos produtos químicos e energia e que os recursos naturais sejam utilizados de forma racional, equilibrada e principalmente adequadamente preservados. A divulgação de técnicas sobre reciclagem, reutilização de materiais, são de suma importância para mostrar o que se pode fazer com os produtos naturais reduzindo a agressão à natureza.

A tintura de tecidos é utilizada há muitos anos e a disponibilidade comercial dos corantes é enorme. O tipo de corante varia de acordo com o tipo de tecido a ser tingido.

Há milhares de anos o homem se valia de corantes de origem mineral, animal e vegetal. Usava-os para o seu próprio adorno, para decorar objetos e utensílios, fazer pinturas e, principalmente, tingir fios e tecidos, que utilizava em seu corpo e em sua casa. (PEZZOLO, 2007, pag. 164)

Os corantes sintéticos são largamente utilizados na indústria têxtil. Entretanto podem causar danos irreversíveis a natureza. Uma pequena quantidade de corante lançada como efluente aquático pode facilmente colorir os rios, produzir danos nas plantações, na fauna e é facilmente detectado pelo ser humano. 
O Cádmio, substância química presente nos pigmentos de tintas e estabilizantes, é altamente tóxico. Ao contaminar o solo ou a água, pode facilmente ser transportado pelos animais, plantas e a lama e assim trazer muitas complicações para os pulmões e rins, podendo assim causar a morte. No Brasil a preocupação com a contaminação ambiental causada pelos pigmentos empregados na indústria têxtil data de 1987 quando a publicação da ABNT NBR 10004. Em 2004 essa resolução foi revisada e ampliada considerando os danos ambientais já existentes e a maior preocupação com a saúde da população e prevenção do aumento das emissões desses resíduos no meio ambiente. (ABNT NBR 2004).

Hoje, devido a maior conscientização e preocupação da sociedade com o meio ambiente, as indústrias tem procurado desenvolver tecnologias adequadas para o tratamento de rios contaminados. No entanto, isso não é suficiente, pois é preciso tratar do problema antes que ele chegue até a natureza. $O$ trabalho de despoluir tem se mostrado muito caro e de eficácia ainda pouco estudada. É preciso descobrir uma forma de tratar os dejetos provenientes do uso de corantes sintéticos antes que eles sejam enviados para a natureza, é necessário que o tratamento desses dejetos seja de obrigatoriedade da indústria.

No Brasil, ao longo do período colonial, os tecidos eram relativamente comuns e produzidos de forma caseira, especialmente os de algodão. Antes mesmo da chegada dos portugueses, varias tribos indígenas, já praticavam a fiação e tecelagem do algodão, cujas espécies eram nativas do Brasil. (LIBBY, 1997)

Até o século XVII, a produção dos tecidos no Brasil era inteiramente de subsistência, dedicada apenas as classes mais pobres, como também ocorria em Portugal. Embora a maior parte da produção fosse de tecidos crus, havia também o tingimento que exigia conhecimentos sobre os corantes naturais, já nas estampas eram utilizadas técnicas próprias de mesclagem das cores dos fios. (NEIRA, 2008)

No século XVIII e XIX, os corantes mais usados pela sociedade mineira eram o anil para cores azuis e a cochonilha e o pau-brasil para cores rubras e avermelhadas. O Brasil foi um grande exportador de corantes naturais para a indústria têxtil européia, principalmente pela extração de pau-brasil. (SILVA et al, 2010). O uso de corantes fez e faz parte de nossa cultura, sempre utilizado na alimentação, no corpo e também nas roupas.

\section{DESENVOLVIMENTO}

\subsection{Os corantes na moda}

A associação internacional ETAD (Ecological And Toxicological Association of the Dyestuff Manufacturing Industry) foi criada em 1974 e focado na fiscalização da fabricação de corantes químicos no mundo. A preocupação da entidade se dá devido a grande quantidade de corantes que são jogados na natureza. Segundo o ETAD, estima-se que cerca de $15 \%$ da produção mundial de corantes químicos são perdidos para o meio ambiente, como uma grande ameaça ao mesmo e conseqüentemente a população. 
Os corantes naturais são um bom exemplo de como podemos utilizar elementos da natureza sem agredi-la e por isso mesmo foram chamados de cores da luz, pois suas cores têm relação direta com a luz do sol. Mesmo que o uso dos corantes químicos tenha se intensificado no mundo contemporâneo, ainda assim muitas pessoas dedicam seus esforços a trabalhar junto a terra, criar peças tecidas e tingidas a mão com produtos naturais. Algumas, inclusive herdaram o conhecimento técnico do uso dos corantes, dos povos das zonas rurais mais antigas do continente. Algumas empresas de moda se dedicam a estudar o uso dos corantes naturais em seus produtos, dentre elas a Pistache \& Banana, Reserva Natural, Justa Trama e Osklen*1.Steiner citado por Ferreira $(1998, p .13)$ afirma que:

Comparar os corantes naturais com os químicos seria como igualar o autêntico à imitação. Ou ainda, quando afirma que os corantes naturais estão para os químicos assim como a orquestra está para o gramofone. (FERREIRA, 1998)

Portanto, acredita-se que o tingimento com corantes naturais sobre produtos do design têxtil são de uma expressão artística única e não podem ser comparados aos produtos químicos e industriais.

A empresa de confecção infantil Pistache \& Banana utiliza do algodão orgânico produzido em Guaricê, no Paraná, para confeccionar suas peças e para tingi-las utiliza-se dos corantes naturais. Assim, os consumidores recebem um produto que não contem artifícios químicos, ficando assim livres de possíveis alergias ou doenças respiratórias. Já a empresa Osklen, utiliza das fundações e-brigade e e-fabrics para desenvolver tecidos totalmente sustentáveis, ou seja economicamente, culturalmente e ambientalmente sustentáveis. Segundo o site da marca, ao conceder a identificação e-fabrics a tecidos e materiais, estes são avaliados a partir de cinco critérios de conformidade: Matérias-primas de origem sustentável, renováveis ou recicladas; impacto do processo produtivo no meio-ambiente natural; resgate e preservação da diversidade e tradições culturais; fomento às relações éticas com comunidades e colaboradores; design, atributos comerciais e viabilidade econômica. Comprando produtos dessas empresas, o consumidor sabe que está contribuindo para uma sociedade mais justa e melhor.

Para o verão 2016, a grife brasileira Osklen, usou em seu desfile uma seda rústica que é produzida através da associação de outras fibras naturais como sisal e rami conforme a figura 1. As plantações onde são cultivados os casulos do bicho da seda são livres de agrotóxicos e as técnicas de produção do tecido são artesanais, gerando mão de obra para as comunidades próximas².

\footnotetext{
${ }^{1}$ Maiores informações podem ser obtidas nos sites: <http://www.osklen.com> acessado em 29/08/2015 $<$ http://www.roupainfantil.org/pistache-banana/ - acessado em 29/08/2015 $<$ http://reservanatural.com.br/a-marca/l> acessado em 29/08/2015 $<$ http://www.justatrama.com.br/home/index.php > acessado em 29/08/2015
}

\footnotetext{
${ }^{2}$ Informação disponível em: <http://www.e-fabrics.com.br/> acessado em 26/08/2015
} 


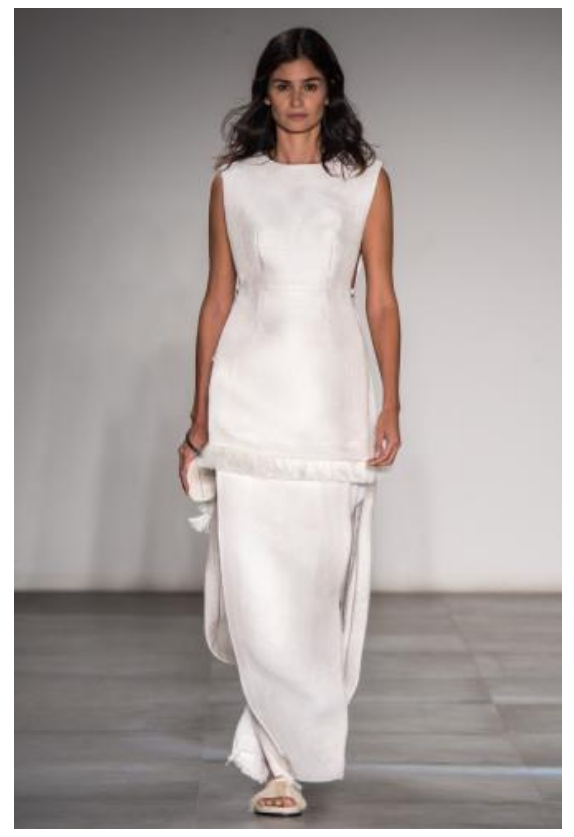

Figura 1 http://www.ecoera.com.br/2015/04/16/seda-rustica-e-destaque-no-verao-daosklen-entenda-essa-e-outras-e-fabrics/ acessado em 25/08/2015

A percepção da importância que vem sendo dada a questão ambiental pode ser também verificada nas ações desenvolvidas por sujeitos que possuem grande visibilidade e capacidade de formação de opiniões, como Gisele Bundchen e Sebastião Salgado.

A modelo mais bem sucedida do Brasil e uma das maiores do mundo, já deixou claro sua preocupação com o meio ambiente. Giselle apóia diversas causas ambientais como o projeto Água Limpa, que é uma iniciativa pessoal da modelo e de sua família com o objetivo de implementar ações de gestão ambiental sustentáveis e promover a recuperação da mata ciliar das bacias de Horizontina e Tucunduca, no Rio Grande do Sul, região onde Giselle nasceu. O fotógrafo brasileiro Sebastião Salgado, reconhecido internacionalmente pelo comprometimento de seu trabalho com populações em situação de vulnerabilidade, realiza em Minas Gerais a recuperação da cobertura vegetal das terras que pertenceram a sua família, se tornando hoje a maior reserva florestal privada do Brasil e do mundo. (SALGADO, 2014)

Vale à pena lembrar a preocupação de ação sustentável presente na São Paulo Fashion Week de 2007 e $2013^{3}$, conforme aponta Maria Luiza Fausto em seu blog expedição vida, e constatado nas propostas de temas e uso de materiais, quando estilistas estabeleceram metas para uso de materiais orgânicos e vindos de fontes sustentáveis. Todo o evento foi organizado procurando compensar a emissão de gás carbônico e reduzir o impacto dos danos de sua

${ }^{3}$ Maiores informações podem ser obtidas nos sites:

http://expedicaovida.com.br/sustentabilidade-na-moda-e-tema-do-spfw-verao-2013/ acessado em 25/08/2015 
própria realização, com medidas de uso de energias limpas, materiais recicláveis e plantação de espécimes vegetais em áreas degradáveis.

Levando em conta que possuímos a maior floresta tropical do planeta, não podemos ignorar a riqueza da biodiversidade e sua pouca utilização pela falta de conhecimento do que podemos ainda extrair dela. Apesar do uso das madeiras de lei, como por exemplo, o paubrasil ter prejudicado a floresta, inclusive colocando algumas espécies sob o risco de extinção por se tratar de um uma atividade extrativista sem o devido controle, a retirada do corante não precisa destruir a espécie.

Os elementos utilizados para a produção da moda fazem parte do conjunto de produtos disponíveis para o designer num momento histórico. Os materiais, acessórios, os tecidos, e até mesmo a forma de produzir as diversas cores e estamparias precisam ser compreendidas como parte dos processos de construção e desenvolvimento cultural de um povo.

O conceito de estar na moda foi ampliado e inclui a preocupação com o meio ambiente, com o desenvolvimento sustentável e fazer algo que contribua para mudar os rumos atuais do consumo e possibilite a interação entre o homem e a natureza de forma mais harmoniosa.

\subsection{A preocupação ambiental}

Com o inicio do novo milênio, o mundo aumenta a sua preocupação com a natureza. Os efeitos do desmatamento das florestas, a poluição dos rios e mares, acabam afetando a vida no planeta e qualidade de vida da população em todos os cantos. As indústrias começam a se adaptar a uma nova era de sustentabilidade. A valorização que parte da população dá a produtos que utilizam produtos menos poluentes, que utilize recursos renováveis, e contribua com a modificação dos comportamentos de consumo, começam a interessar o empresariado brasileiro. Assim, os corantes naturais podem ser uma alternativa para minimizar a a contaminação do solo e dos rios provocados pelos produtos químicos sintéticos na natureza. 0 estudioso Ferreira (1998), apresenta receitas de como usar a flora brasileira para fazer tingimentos e mostra a história cronológica do processo de tingimento dos tecidos desde 4000 A.C. até 1992 D.C.

A sociedade atual vive um momento de consumo desenfreado. A Revolução industrial trouxe para sociedade da época, uma nova forma de consumir, pois as máquinas faziam o trabalho do homem, dando inicio a produção em escala dos produtos. A partir da década de 60 , com o aparecimento de supermercados, shoppings centers a política de consumo mudou radicalmente. Segundo Guerra (2010), os movimentos sociais dos anos 60, os hippies e os punks, ajudaram no processo de seleção e combinação de consumo, colaborando na criação de padrões dos produtos. Os bens de consumo são produzidos para durar certo tempo, depois que esse tempo se expira, o homem joga fora e compra um novo. Não existe a política de conserto ou de troca de peças. Vale mais a pena comprar um produto novo do que mandar consertar qualquer produto que esteja com defeito. Como conseqüência, as pessoas vão consumindo mais e despejando na natureza restos de produtos que não utilizam. 
O consumismo coloca a "sociedade de consumidores" em movimento como um a forma específica de convívio humano, estabelecendo simultaneamente parâmetros e manipulando as estratégias individuais de vida e as possibilidades de escolha. Na sociedade contemporânea, assim, as relações interpessoais são caracterizadas como os meios e objetos do consumo. Segundo essa perspectiva, a passagem do consumo ao consumismo ocorre no momento que o consumo torna-se o aspecto central da vida de grande parte das pessoas e quando o convívio entre os homens passa a ser orientado pelas emoções ligadas ao consumo, como o querer, o desejar e o ansiar por alguma coisa específica. (GUERRA, 2010 pag. 55)

Em 1992, uma grande mobilização mundial demonstrou de forma mais clara que o mundo começava a se preocupar com as questões ambientais. A eco-92, realizada no Rio de Janeiro nessa época, foi um grande passo para um início de mudança de pensamento da sociedade. Durante essa conferência, os países membros da ONU presentes no evento, assinaram o documento chamado de Agenda 21. Este documento fez com que os países discutissem e refletissem sobre a forma como os governos, organizações não governamentais, empresas e diversos setores da sociedade deveriam cooperar na tentativa de resolver os problemas socioambientais. Conforme, Jacobi (2000):

O ambientalismo do século XXI tem uma complexa agenda pela frente. De um lado, o desafio de ter uma participação cada vez mais ativa na governabilidade dos problemas socioambientais e na busca de respostas articuladas e sustentadas em arranjos institucionais inovadores que possibilitem uma "ambientalização dos processos sociais", dando sentido à formulação e implementação de uma agenda 21 nos níveis nacional e subnacional. De outro, a necessidade de ampliar o escopo de sua atuação, através de redes, consórcios institucionais, parcerias estratégicas e outras engenharias institucionais que ampliem seu reconhecimento na sociedade e estimulem o engajamento de novos atores na definição de uma agenda que acelere prioridades para a sustentabilidade como um novo paradigma de desenvolvimento. (JACOBI, 2000 pag. 03)

Em 1997, na cidade japonesa de Kyoto, foi proposto para assinatura o Protocolo com o mesmo nome da cidade, que tinha como objetivo reduzir em $5,2 \%$, a emissão de gases poluentes, entre os anos de 2008 e 2012.

A recente vigência do Protocolo de Kyoto, em fevereiro de 2005, é um marco institucional nas tentativas de ação coletiva visando à mitigação das mudanças climáticas. O Protocolo contém o comprometimento dos países industrializados e dos países cujas economias estão em transição, com metas de redução de emissões de GEE (gases de efeito estufa). (ANDRADE e COSTA 2008 pag. 31)

O protocolo sugeria que essas ações fossem feitas por vários setores da sociedade e que os países signatários aumentassem o uso de fontes de energias limpas, protegessem as florestas e áreas verdes, melhorassem os sistemas de energia e transporte para um uso mais 
racional, diminuindo assim as emissões do gás metano, que está presente em sistemas de depósito de lixo. Ainda sugeriam a definição de regras para a emissão dos créditos de carbonos. Entretanto, alguns países se recusaram a assinar o protocolo, e somente com $55 \%$ das assinaturas dos países que emitiam poluentes na natureza, é que o protocolo poderia ser ratificado. Somente em 16 de fevereiro de 2005, o protocolo foi ratificado, depois que a Rússia decidiu pela sua assinatura. Os Estados Unidos mantiveram a posição de não assinar, alegando que a diminuição dos gases poluentes poderia afetar a economia norte-americana. Entretanto, essa posição não é homogênea e a divergência interna tem levado a alguns estados, como a Califórnia a procurar soluções para diminuir a emissão dos gases poluentes sem diminuir sua margem de lucro.

Em 2009, em Copenhague, uma nova tentativa para a diminuição das emissões de carbono e formas de fortalecer ações de cooperações entre os países reuniu as principais nações do mundo, tanto as maiores poluidoras, quanto aquelas que lutam por um planeta mais limpo. A conferência ficou conhecida como COP15, e na agenda estavam além das ações citadas acima, o auxílio financeiro aos países em desenvolvimento.

\section{CONCLUSÃO}

A sociedade vive então, um momento de bastante preocupação ambiental, mas as pessoas estão começando a reagir a esses problemas, ainda que isoladamente, sem a ajuda de governos locais ou globais. $O$ designer pode ter um papel fundamental nesse processo, pois uma vez que ele pode interferir em todo o processo de produção nesta indústria, tais como a forma de utilização, aproveitamento e controle dos tecidos, a capacidade de projetar uma roupa de forma mais sustentável sem afetar o design e a produtividade, e finalmente calcular os riscos que essas mudanças podem causar a empresa e a sociedade.

A indústria da moda já está fazendo sua parte nessa difícil tarefa. A utilização de fibras naturais e corantes naturais por estilistas italianos está motivando estilistas do mundo inteiro a fazer o mesmo. A não utilização de peles de animais e modelos apoiando a causa é também um grande passo.

É possível concluir que os corantes sintéticos/químicos precisam ser melhor estudados e analisados para minimizar os efeitos maléficos que podem trazer a natureza. $E$ também que os corantes naturais podem e devem ser utilizados de uma forma mais ampliada pela população e pela indústria têxtil, uma vez que já se comprovou a eficácia desses.

Reflexões desse tipo podem levar a população a buscar novos hábitos de consumo. Preocupando-se coletivamente com o planeta e assumindo ações individuais que permitem alterar de forma efetiva os danos à natureza.

\section{REFERÊNCIAS}

ABNT - Associação Brasileira de Normas Técnicas. NBR 10004 Resíduos sólidos. Disponível em: <http://www.aslaa.com.br/legislacoes/NBR\%20n\%2010004-2004.pdf > Acesso em $15 / 11 / 2010$. 
AÇOES sustentáveis. Disponível em http://expedicaovida.com.br/sustentabilidade-namoda-e-tema-do-spfw-verao-2013/ acessado em 25/08/2015

ANDRADE, José Célio Silveira and COSTA, Paulo. Mudança climática, protocolo de Kyoto e mercado de créditos de carbono: desafios à governança ambiental global. Organ. Soc. [online]. 2008, vol.15, n.45 [cited 2015-08-29], pp. 29-45 . Available from: $<$ http://www.scielo.br/scielo.php?script=sci_arttext\&pid=S198492302008000200002\&lng=en\&nrm=iso>. ISSN 1984-9230. http://dx.doi.org/10.1590/S198492302008000200002.

BARBOSA Rubens. O Brasil e a conferência de Copenhague. Estadão.com.br, 26 de janeiro de 2010. Disponível em:<http://www.portalodm.com.br/conferencia-de-copenhague-cop-15--e-24.html> acesso em 15/11/2010

BOLZANI, VS. VIEGAS jr, C. BARREIRO, EJ. Os produtos naturais e a química medicinal moderna. Quimica Nova. Vol 29 No 2, 326-37, 2006

CORANTES Naturais. Disponível em: <http://www.sitecurupira.com.br $>$ Acessado em $19 / 11 / 2007$

FERREIRA, Eber Lopes. Corantes Naturais da Flora Brasileira: Guia Prático de Tingimento com Plantas. Curitiba: Optagraf Editora e Gráfica LTDA, 1998.

GUARATINI, CCI. ZANONI, MVB. Corantes têxteis. Quimica Nova vol 23(1)71-78 (2000)

GUERRA, Renata de Souza. Dimensões do consumo na vida social. 2010. 261f. Tese (doutorado) - Universidade Federal de Minas Gerais, Faculdade de Filosofia e Ciências Humanas.

JACOBI, Pedro. Meio ambiente e redes sociais: dimensões intersetoriais e complexidade na articulação de práticas coletivas In: Revista de Administração Pública Rio de Janeiro 34(6):13158, Nov. /Dez . 2000

LE GOFF, J. História e Memória. 4ạed. Campinas: Unicamp, 1986.

LEVER, J. A Roupa e a Moda: Uma História Concisa. São Paulo: Companhia das Letras, 2006. $285 \mathrm{p}$.

LIBBY, Douglas Cole. Notas sobre a produção têxtil brasileira no final do século XVIII:

MENDES, V.; HAYE, A. A Moda do Século XX. São Paulo: Martins Fontes, 2003. 314 p.

NEIRA, Luz Garcia. O Design Têxtil no Brasil em Três Tempos: Um Estudo Exploratório. São Paulo: Anais do 8 Congresso Brasileiro de Pesquisa e Desenvolvimento em Design, 2008. Disponível em http://www.designbrasil.org.br/design-em-pauta/8o-pd-saopaulo/\#.VeHDs5cX4j- acessado em 25/08/2015

Novas evidências de Minas Gerais. Estudos Econômicos, v. 27, no 1, p. 97-125. São Paulo: jan.abr., 1997. 
PEZZOLO, Dinah Bueno. Tecidos: história, tramas, tipos de usos. São Paulo: Ed.: Senac São Paulo, 2007. 324p.

PREOCUPAÇÃO ambiental na moda. Disponível em <http://www.osklen.com> acessado em $29 / 08 / 2015$

PREOCUPAÇÃO ambiental na moda. Disponível em <http://www.roupainfantil.org/pistache-banana/ acessado em 29/08/2015

PREOCUPAÇÃO ambiental na moda. Disponível em <http://reservanatural.com.br/a-marca/> acessado em 29/08/2015

PREOCUPAÇÃO ambiental na moda. Disponível em

<http://www.justatrama.com.br/home/index.php> acessado em 29/08/2015

PROTEÇÃO das manufaturas de tecidos nacionais. Disponível em

http://www.historiacolonial.arquivonacional.gov.br/cgi/cgilua.exe/sys/start.htm?infoi $\mathrm{d}=988 \&$ sid $=107$ Acessado em $01 / 06 / 2010$ as $10: 00$

SALGADO, Sebastião. Da Minha Terra à Terra. São Paulo: Ed. Paralela, 2014.

SEDA rústica. Disponível em http://www.ecoera.com.br/2015/04/16/seda-rustica-edestaque-no-verao-da-osklen-entenda-essa-e-outras-e-fabrics/ acessado em 25/08/2015

SCHULTE, N. NARDI, A. VIVIAN AC. Consumo consciente: Um desafio para o design de moda. V Jornada de iniciação Cientifica Centro de Artes da UDESC disponível em <HTTP://www.ceart.udesc.br/revista_dapesquisa/vol4/1/moda/consumoconsc.pdf. acesso em 18 de out 2010

ZEILLON, D. Moda e Guerra: Um Retrato da França Ocupada. Rio de Janeiro: Zahar, 2004. 